\title{
Produção de antissoro policlonal utilizando a proteína capsidial recombinante do Rupestris stem pitting-associated virus
}

\author{
Production of polyclonal antiserum using recombinant coat protein of Rupestris \\ stem pitting -associated virus
}

\author{
Marcos Fernando Basso ${ }^{I}$ Thor Vinícius Martins Fajardo ${ }^{I{ }^{*}}$ Marcelo Eiras $^{\text {III }}$ \\ Ricardo Antônio Ayub ${ }^{\mathrm{I}}$ Osmar Nickel ${ }^{\mathrm{II}}$
}

\section{- NOTA -}

\section{RESUMO}

\begin{abstract}
O Rupestris stem pitting-associated virus (RSPaV) é o agente causal das caneluras do lenho da videira. Este trabalho teve como objetivo produzir antissoro policlonal a partir da proteina capsidial (CP) recombinante do RSPaV e avaliar a sua especificidade e sensibilidade. $O$ gene da $C P$ do RSPaV, com 780pb, foi previamente caracterizado. Esse gene foi subclonado no sítio de restrição EcoRI, no vetor de expressão pRSET-B e o plasmídeo recombinante foi utilizado para induzir a expressão da CP em Escherichia coli. $A$ CP, ligada a uma cauda de seis histidinas, foi purificada por meio de cromatografia de afinidade em coluna de Ni-NTA a partir do extrato de proteinas totais extraídas de $\boldsymbol{E}$. coli. A identidade da proteina purificada foi confirmada em SDS-PAGE e Western blot, utilizando-se anticorpos comerciais contra a cauda de seis histidinas. A CP recombinante expressada in vitro apresentou massa molecular de cerca de $31 \mathrm{kDa}$. A proteina purificada foi quantificada e 2,55mg foram utilizados para a imunização de um coelho. $O$ antissoro policlonal obtido reagiu com diferentes isolados deste virus, extraídos de videiras em ELISA indireto.
\end{abstract}

Palavras-chave: videira, RSPaV, detecção, sorologia.

\section{ABSTRACT}

RSPaV is the causal agent of pitting in the grapevine woody cylinder. The aim of this research was to produce polyclonal antiserum against recombinant RSPaV coat protein $(C P)$ and evaluate its specificity and sensibility. The CP gene (780bp) of RSPaV was previously characterized. This gene was subcloned into the EcoRI site of the pRSET-B expression vector and the recombinant plasmid was used to induce the expression of the $C P$ in $\boldsymbol{E}$. coli cells. The CP, fused to a 6-His-tag, was purified from $\boldsymbol{E}$. coli total protein extract by affinity chromatography using Ni-NTA resin. Identity of the purified protein was confirmed by SDS-PAGE and Western blot, using antibodies against the histidine tail. The in vitro-expressed recombinant $C P$ presented a $M W$ of ca. $31 \mathrm{kDa}$. The purified protein was quantified and $2.55 \mathrm{mg}$ used for the immunization of a rabbit. The obtained polyclonal antiserum reacted with different RSPaV isolates extracted from grapevines in indirect ELISA.

Key words: grapevine, RSPaV, detection, serology.

O Rupestris stem pitting-associated virus (RSPaV), gênero Foveavirus, foi identificado e caracterizado molecularmente como agente causal das caneluras do tronco de Rupestris, causando alterações no lenho e declínio em videiras, com reflexos negativos na quantidade e qualidade da produção (RADAELLI et al., 2009). Por sua versatilidade e praticidade, a sorologia tem sido indicada para a diagnose de vírus, especialmente quando há maior número de amostras, com destaque para o ELISA, utilizando antissoros policlonais específicos (BASSO, 2010). No momento, não há disponibilidade de antissoros comerciais contra o RSPaV e, em especial, contra isolados locais, o que dificulta a detecção sorológica desse vírus. Considerando-se a variabilidade genética existente no gene da proteína capsidial (CP) entre isolados de $\mathrm{RSPaV}$,

'Departamento de Fitotecnia e Fitossanidade, Universidade Estadual de Ponta Grossa (UEPG), 84030-900, Ponta Grossa, PR, Brasil.

"Embrapa Uva e Vinho, Bento Gonçalves, RS, Brasil. E-mail: thor@cnpuv.embrapa.br. *Autor para correspondência.

IIIInstituto Biológico, Centro de Pesquisa e Desenvolvimento de Sanidade Vegetal (CPDSV), São Paulo, SP, Brasil. 
contando inclusive com a definição de quatro grupos de isolados por ALABI et al. (2010), a produção de um antissoro contra a $\mathrm{CP}$ de um isolado específico desse vírus pode constituir-se em uma importante ferramenta para a detecção do RSPaV, se tal anticorpo apresentar a propriedade de reconhecer diferentes isolados.

A purificação viral, visando à produção de antissoros, é um processo trabalhoso e, comumente, pode resultar em preparações com pureza e concentrações insatisfatórias, comprometendo a qualidade do antissoro produzido (FAJARDO et al., 2007). Especificamente, em relação à purificação de partículas do RSPaV a partir da videira, dificuldades adicionais são mencionadas: a inexistência de hospedeiras herbáceas para a manutenção e multiplicação deste vírus; a constante presença de complexos virais, com possibilidade muito restrita de isolamento biológico; a característica lenhosa dessa planta e a presença de compostos polifenólicos que se oxidam facilmente; a baixa concentração viral na planta infectada, restrita ao floema. Os objetivos deste trabalho foram expressar o gene da proteína capsidial do $\mathrm{RSPaV}$ em Escherichia coli, produzir um antissoro policlonal e avaliar sua especificidade e sensibilidade na detecção de diferentes isolados desse vírus.

O gene completo da proteína capsidial (CP) do isolado viral de RSPaV (com 780pb e 259 aminoácidos deduzidos), denominado CF207, foi previamente caracterizado por RADAELLI et al. (2009). $\mathrm{O}$ gene da CP do RSPaV foi removido do plasmídeo pGEM-T Easy (Promega) pela digestão com a enzima de restrição $E c o$ RI, eluído a partir de gel de agarose e, posteriormente, ligado ao vetor de expressão pRSET-B (Invitrogen), previamente digerido com EcoRI (SAMBROOK \& RUSSEL, 2001).

Para a expressão in vitro, a construção pRSET-B/CP RSPaV foi transferida para a estirpe BL21:DE3 de $\boldsymbol{E}$. coli, utilizando-se a transformação por choque térmico. Após cultivo em meio de cultura LB sólido com ampicilina ( $\left.100 \mathrm{mg} \mathrm{mL}^{-1}\right)$, uma colônia isolada foi cultivada por $12 \mathrm{~h}$, sob agitação, a $37^{\circ} \mathrm{C} \mathrm{em} 5 \mathrm{~mL}$ de meio de cultura LB líquido com ampicilina. Esse préinóculo foi utilizado para o cultivo de $200 \mathrm{~mL}$ de LB líquido com ampicilina, incubando-se a $37^{\circ} \mathrm{C}$ até atingir $\mathrm{OD}_{(600 \mathrm{~nm})}$ de 0,5 . Neste ponto, a expressão da $\mathrm{CP}$ foi induzida por adição de IPTG $(2 \mathrm{mM})$ e, $6 \mathrm{~h}$ após a indução, as células foram coletadas por centrifugação (6000g por $10 \mathrm{~min})$. No total, a expressão do gene foi induzida em $700 \mathrm{~mL}$ de cultivo bacteriano.

Um extrato de proteínas totais de $\boldsymbol{E}$. coli foi obtido conforme descrito por FAJARDO et al. (2007), segundo protocolo não desnaturante. A proteína $\mathrm{CP} /$ $\mathrm{RSPaV}$ foi purificada por cromatografia de afinidade em coluna de resina Ni-NTA (Qiagen), conforme instruções do fabricante e avaliada por eletroforese em gel de poliacrilamida e por Western blot (SAMBROOK \& RUSSEL, 2001), utilizando-se antissoro comercial (Invitrogen) contra a cauda de seis histidinas da proteína expressada. A quantificação da proteína purificada foi obtida por espectrofotometria de absorbância (280nm).

Foram realizadas cinco aplicações intramusculares em coelho, a primeira delas com adjuvante completo de Freund e as demais com adjuvante incompleto, a intervalos semanais, com dosagens de 250, 350, 500, 650 e $800 \mathrm{mg}$ de proteína por imunização. Uma semana após a última imunização, iniciaram-se as nove coletas de sangue $\left(30 \mathrm{~mL}\right.$ sangria $\left.{ }^{-1}\right)$, realizadas a intervalos também semanais, sendo o sangue processado conforme RADAELLI et al. (2008) para a obtenção do antissoro. A purificação da fração $\mathrm{IgG}$ foi realizada por cromatografia de troca iônica em coluna de DEAE-SEPHACEL e quantificada por espectrofotometria (FAJARDO et al., 2007). A sensibilidade e a especificidade do antissoro produzido foram avaliadas em ELISA indireto (RADAELLI et al., 2008), com amostras de videiras sadias ou infectadas por 12 diferentes isolados de $\mathrm{RSPaV}$ dos quais oito foram previamente caracterizados molecularmente (RADAELLI et al., 2009; BASSO, 2010).

Visando avaliar a eficiência da detecção sorológica de diferentes isolados de RSPaV com o antissoro produzido contra o isolado CF207, determinou-se a percentagem de identidade de nucleotídeos do gene CP completo deste isolado em relação a oito isolados caracterizados anteriormente (RADAELLI et al., 2009; BASSO, 2010). As comparações entre sequências foram realizadas utilizando-se os programas BLASTn e BLASTp do NCBI (http://www.ncbi.nlm.nih.gov).

A expressão da $\mathrm{CP}$ do $\mathrm{RSPaV}$, na estirpe BL21:DE3 de $\boldsymbol{E}$. coli, foi induzida quatro vezes num total de $700 \mathrm{~mL}$ de meio de cultivo, resultando na obtenção de 2,55; 3,10;3,38 e 3,12mg de proteína capsidial recombinante do $\mathrm{RSPaV}$ em cada procedimento, com rendimento médio de $17,35 \mu \mathrm{g} \mathrm{mL}^{-1}$ de meio de cultura. Esses resultados são semelhantes aos rendimentos médios de $\mathrm{CP}$ recombinantes expressadas para outros vírus de videira (FAJARDO et al., 2007; RADAELLI et al., 2008).

A tradução do gene inserido no vetor recombinante resultou em uma proteína de fusão com cerca de $28 \mathrm{kDa}$, correspondente à $\mathrm{CP}$ do $\mathrm{RSPaV}$, acrescido de aproximadamente $3 \mathrm{kDa}$ advindos dos aminoácidos ligados ao $\mathrm{N}$-terminal da $\mathrm{CP}$ que constituem a "cauda" de seis histidinas, a qual permite a retenção da proteína de fusão em coluna de Ni-NTA no processo de purificação (Figura 1A). A identidade da proteína expressada foi confirmada pela reação positiva com anticorpos contra histidina (Figura 1B). 


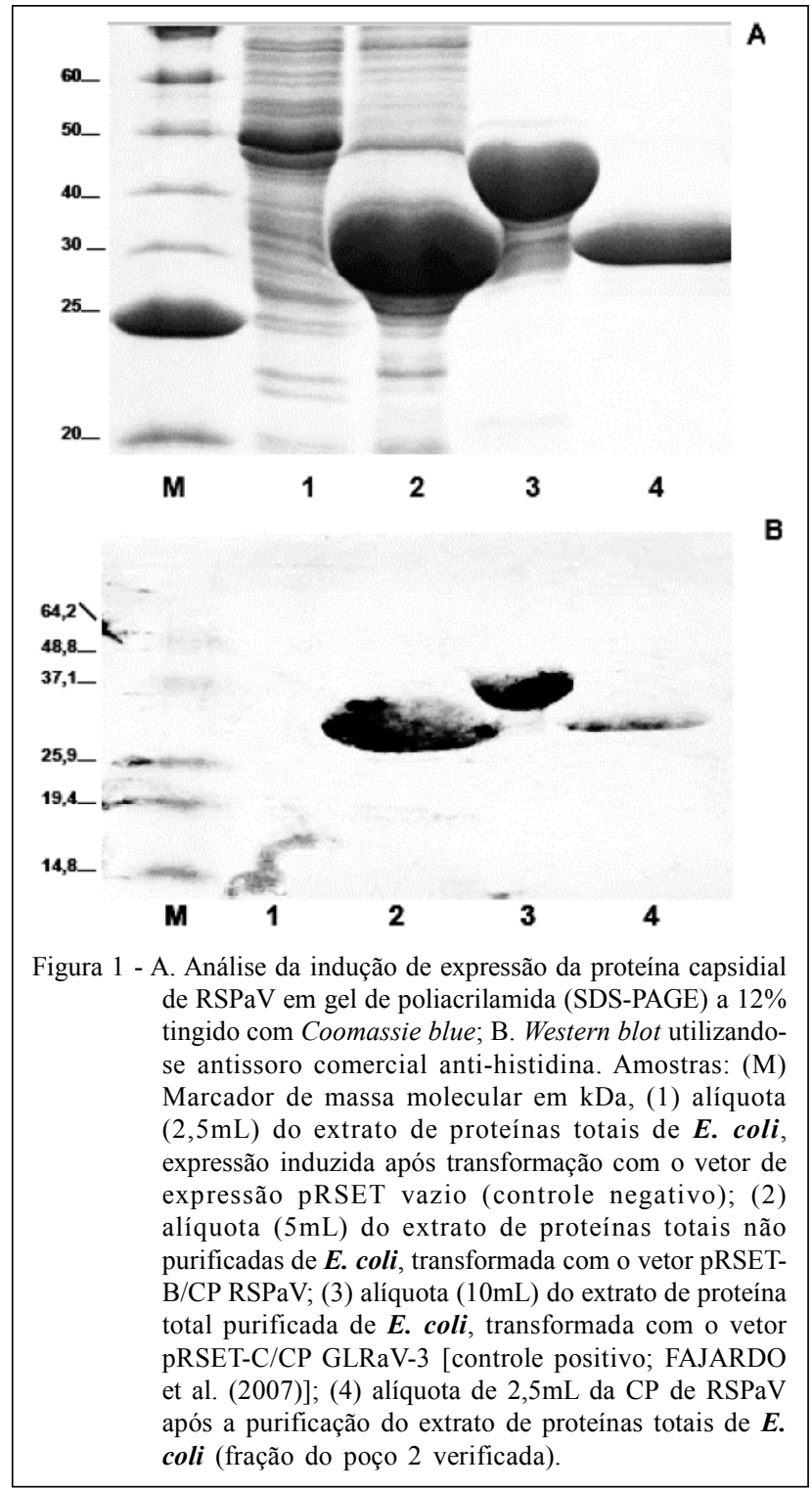

Após a purificação da $\operatorname{IgG}$ a partir do antissoro produzido, esta foi quantificada apresentando concentração de, aproximadamente, $1900 \mathrm{mg} \mathrm{de} \mathrm{IgG} \mathrm{mL}^{-1}$.

Os resultados dos testes de ELISA indiretos demonstraram que o antissoro produzido a partir da proteína expressada é específico na detecção do RSPaV. Foram verificadas reações homólogas com extratos de plantas infectadas com 12 diferentes isolados desse vírus (Tabela 1). Outros autores (MINAFRA et al., 2000; MENG et al., 2003) produziram antissoros contra a proteína capsidial recombinante de diferentes isolados de $\mathrm{RSPaV}$ com resultados distintos, em função da capacidade do anticorpo reconhecer a proteína viral nativa ou desnaturada em diferentes tipos de testes sorológicos.
Diferenças observadas nas sequências de nucleotídeos (nt) ou de aminoácidos deduzidos (aad) do gene da proteína capsidial podem ter efeito sobre as funções desta proteína, incluindo seu relacionamento sorológico, uma vez que alguns epitopos na proteína capsidial são a base para que os anticorpos os reconheçam e possam reagir em ELISA (FAJARDO et al., 2007). A análise de identidade das sequências de nt e aad, correspondente ao gene da proteína capsidial do isolado CF207 e sequências homólogas de outros isolados deste vírus, demonstrou que o isolado CF207 apresentou identidades de nucleotídeos variando de 84,6\% (CF195) a 96,5\% (420A e MG) e de aminoácidos deduzidos variando de $88 \%$ (CS1) a 98,1\% (420A e MG). O antissoro produzido 
Tabela 1 - Resultados do teste ELISA indireto com amostras de videiras infectadas com RSPaV, utilizando-se o antissoro produzido contra a CP do RSPaV, expressada e purificada a partir de células de $\boldsymbol{E}$. coli. Valores das leituras de absorbância, no comprimento de onda de $405 \mathrm{~nm}$, aproximadamente, $2 \mathrm{~h}$ após a adição de substrato e em duas concentrações da IgG. Amostra positiva apresenta valor de absorbância, no mínimo, duas vezes superior ao verificado para a amostra sadia.

\begin{tabular}{|c|c|c|c|c|}
\hline \multirow[t]{2}{*}{ Amostra } & \multirow[t]{2}{*}{ Isolado viral } & \multirow{2}{*}{$\begin{array}{c}\text { Código da sequência de } \\
\text { nucleotídeos do gene } \\
\text { CP do RSPaV no } \\
\text { GenBank }\end{array}$} & \multicolumn{2}{|c|}{$\begin{array}{c}\text { Absorbância }(405 \mathrm{~nm}) \\
\text { Concentração da } \operatorname{IgG}\left(\mu \mathrm{g} \mathrm{mL}^{-1}\right)\end{array}$} \\
\hline & & & 2 & 4 \\
\hline Rupestris du Lot (sadia) & - & - & $0,158(-)$ & $0,314(-)$ \\
\hline Cabernet Franc (Q5 P207) & CF207 & EF636804 ${ }^{(1)}$ & $0,487(+)$ & $0,925(+)$ \\
\hline $420 \mathrm{~A}$ & $420 \mathrm{~A}$ & EU040204 ${ }^{(1)}$ & $0,517(+)$ & $0,821(+)$ \\
\hline Moscato Giallo & MG & EF690380 & $0,796(+)$ & $1,025(+)$ \\
\hline Cabernet Franc (Q5 P210) & $\mathrm{CF} 210$ & EF690384 ${ }^{(1)}$ & $0,653(+)$ & $0,848(+)$ \\
\hline Cabernet Franc (Q5 P195) & CF195 & $\mathrm{EF} 636803^{(1)}$ & $0,691(+)$ & $0,919(+)$ \\
\hline Pinot Nero & $\mathrm{PN}$ & EF690381 ${ }^{(1)}$ & $1,093(+)$ & $1,710(+)$ \\
\hline Cabernet Sauvignon (planta 1) & $\mathrm{CS} 1$ & GU166289 (2) & n.d. & $1,724(+)$ \\
\hline Isabel (planta 2) & IS $2 a$ & GU166290 (2) & n.d. & $1,097(+)$ \\
\hline Cabernet Franc (Q5 P213) & CF213 & - & $0,640(+)$ & $1,203(+)$ \\
\hline Cabernet Franc (Q5 P152) & CF152 & - & $0,628(+)$ & $0,864(+)$ \\
\hline Cabernet Franc (Q5 P210-2) & CF210-2 & - & $0,471(+)$ & $0,691(+)$ \\
\hline Trebbiano Toscano & TT & - & $0,713(+)$ & $1,121(+)$ \\
\hline
\end{tabular}

- = isolado de RSPaV não caracterizado molecularmente; n.d. = não determinado; isolados caracterizados molecularmente com base na sequência completa de nucleotídeos do gene CP $^{(1)}$ (RADAELLI et al., 2009) $\mathrm{e}^{(2)}($ BASSO, 2010).

contra a CP expressada do RSPaV, isolado CF207, reagiu com todos os isolados testados desse vírus, incluindo os isolados mais distantes filogeneticamente (CF195, $\mathrm{PN}, \mathrm{CS} 1, \mathrm{IS} 2 \mathrm{a})$, os quais diferiram em até $15,4 \%$ e $12 \%$ de identidade de nt e aad, respectivamente, em relação ao isolado CF207. Resultados semelhantes foram obtidos por RADAELLI et al. (2008), com um antissoro produzido contra a CP recombinante do GLRaV-2, ao verificarem reações positivas contra diferentes isolados desse vírus que apresentavam significativa variabilidade genética.

\section{COMITÊ DE ÉTICA E BIOSSEGURANÇA}

O Certificado de Qualidade em Biossegurança (CQB) da Embrapa Uva e Vinho está registrado na Comissão Técnica Nacional de Biossegurança (CTNBio) sob o número 0227/06.

\section{REFERÊNCIAS}

ALABI, J.A. et al. Sequence diversity, population genetics and potential recombination events in Grapevine rupestris stem pitting-associated virus in Pacific North-West vineyards. Journal of General Virology, v.91, p.265-276, 2010.

BASSO, M.F. Desenvolvimento de ferramentas sorológicas e moleculares para identificação de vírus em videiras e cochonilhas, alterações fisiológicas e na qualidade enológica da uva de videiras infectadas. 2010. $114 \mathrm{f}$. Dissertação (Mestrado em Agronomia) - Curso de Pós-graduação em Agronomia, Universidade Estadual de Ponta Grossa, PR.
FAJARDO, T.V.M. et al. Expression of Grapevine leafrollassociated virus 3 coat protein gene in E. coli and production of polyclonal antibodies. Fitopatologia Brasileira, v.32, p.496-500, 2007. Disponível em: <http://www.scielo.br/pdf/ fb/v32n6/a07v32n6.pdf>. Acesso em: 04 out. 2010. doi: $10.1590 / \mathrm{S} 0100-41582007000600007$.

MENG, B. et al. Antiserum to recombinant virus coat protein detects Rupestris stem pitting associated virus in grapevine. Plant Disease, v.87, p.515-522, 2003. Disponível em: <http:/ /apsjournals.apsnet.org/doi/pdf/10.1094/PDIS.2003.87.5.515>. Acesso em: 04 out. 2010. doi: 10.1094/PDIS.2003.87.5.515.

MINAFRA, A. et al. Serological detection of Grapevine rupestris stem pitting-associated virus by a polyclonal antiserum to recombinant virus coat protein. Vitis, v.39, p.115-118, 2000. Disponível em: <http://www.vitis-vea.de/admin/volltext/ e046265.pdf>. Acesso em: 04 out. 2010.

RADAELLI, P. et al. Production of polyclonal antisera using recombinant coat proteins of Grapevine leafroll-associated virus 2 and Grapevine virus B. Pesquisa Agropecuária Brasileira, v.43, p.1405-1411, 2008. Disponível em: <http:/ /www.scielo.br/pdf/pab/v43n10/20.pdf>. Acesso em: 04 out. 2010. doi: 10.1590/S0100-204X2008001000020.

RADAELLI, P. et al. Variabilidade do gene da proteína capsidial de três espécies virais que infectam videiras no Brasil. Tropical Plant Pathology, v.34, p.297-305, 2009. Disponível em: $<$ http://www.scielo.br/pdf/tpp/v34n5/v34n5a02.pdf $>$. Acesso em: 04 out. 2010. doi: 10.1590/S1982-56762009000500002.

SAMBROOK, J.; RUSSEL, D. Molecular cloning: a laboratory manual. 3.ed. New York: Cold Spring Harbor Laboratory, 2001. 999p. 